Thorax, 1979, 34, 569-570

\title{
Correspondence
}

\section{Per cent of predicted as the limit of normal in pulmonary function testing: a statistically valid approach}

Sir,-Drs Sobol and Sobol (editorial, February 1979) effectively demolish the logic of using $80 \%$ of predicted as the lower limit of normality in pulmonary function tests. (Perhaps I have led a sheltered life, but I was unaware that such a practice could be regarded as traditional; I am fairly sure that it is not, in this country at least.)

I must, however, utter the warning that the suggestion they make for improving the procedure by making it "statistically valid" offers to replace one illogicality by another. Omniscient as statisticians are, their ability to diagnose abnormality is not generally acknowledged by the medical community, and indeed they usually refrain from claiming it. This is perhaps because the Normal distribution, if it fits normal subjects (as it often does), indicates that $2 \frac{1}{2} \%$ of normal subjects will have values two standard deviations or more below the mean of the Normal curve, not that the Normal curve stops dead at two standard deviations from the mean so that all below are abnormal.

Only if an individual is chosen at random from a general population known to be Normally distributed, and found to have a lung function test two standard deviations below average, could one suspect that he probably belongs to some other, abnormal population. In clinical practice patients are never picked at random to be sent to lung function laboratories; they are sent because they are thought to be abnormal. The normal reference population therefore has no relevance, and any probabilistic interpretation of a deviation of two standard deviations is wrong.

In epidemiological studies the subjects' lung function measurements may be found to fit Normal distribution curves quite closely. If this is to be assumed, then again no individual can be picked out as abnormal, because the Normal distribution is all-embracing.

The dangers of supposing that statistical arguments can compensate for ignorance of the actual implications of a particular test result (not only in lung function) are obvious. Possibly more subtly concealed are the dangers of the tacit assumption that what is ever wanted is a division of patients into normal and abnormal. Surely it is the relative magnitudes of deviations from the usual of a variety of aspects of lung function that have to be jointly assessed, to establish the direction in which the degree of abnormality is tending (Oldham, 1970). Would a series of decisions of "normal" or "abnormal" help to clarify the interpretation of an FEV of 1.21 and FVC of $2 \cdot 11$ and a $\mathrm{PaO}_{2}$ of 60 torr $(8 \mathrm{kPa})$ in an
African with severe kyphoscoliosis, aged 49, height $1.54 \mathrm{~m}$, weight $40.7 \mathrm{~kg}$, who had been an asbestos miller for 23 years? Pickering (1978) has recently reminded us, once again, that the custom persists of dividing arterial blood pressure into normotension and hypertension to facilitate diagnosis, and that he has no doubt that this practice does untold harm to the patient. Is it not equally true that to treat quantitative tests of lung function as if they were qualitative, by an unjustified appeal to statistical theory, is not only fallacious but a hindrance to understanding?

\section{P D OLDHAM \\ MRC Pneumoconiosis Unit, Llandough Hospital, Penarth, S Glamorgan CF6 $1 X W$}

\section{References}

Oldham, P D (1970). The uselessness of normal values. In Introduction to the Definition of Normal Values for Respiratory Function in Man, edited by $\mathbf{P}$ Arcangeli, pp 49-56. Panminerva Medica, Torino. Pickering, Sir George (1978). Normotension and hypertension: the mysterious viability of the false. American Journal of Medicine, 65, 561-563.

REPLY - In response to the letter of Dr Oldham we would point out that in the United States the use of $80 \%$ of predicted as a dividing line separating normal from abnormal is a common practice and has been for decades. It has been advocated as the limit of normal by pulmonary physiologists of considerable eminence, and Englishmen at that, Bates and Christie in their textbook on pulmonary disease. Whether or not decades of use can be considered to lend something the aura of tradition seems to us a petty point. But physicians do use some fixed percentage below which they consider a subject as abnormal, and it was this use of percentage to which our article was addressed.

We could not agree with Dr Oldham more in his insistence on the inadequacy of statistics and the frequent ludicrous division of subjects into normal and abnormal across a narrow dividing line. However, in the absence of such dividing lines the presentation of subjects in scientific papers would become merely anecdotal; controlled studies on the course of disease, on therapy would all become impossible. No reasonable person would dispute that, in dealing with the individual subject, judgment, intuition, common sense, and all those things which in combination make for the clinician and good practitioner should be brought 
to bear. But the language of science is numbers. If we are to understand each other we must speak the same language, and this language must be as precise as scientists can make it. Unhappily for us in the biological sciences the language remains poor at best. Our article represented a small effort, and in Dr Oldham's view a poor effort, to bring a modicum of precision to an aspect of medicine and physiology which sadly has seen much too much art and too little science.

BRUCE J SOBOL

PETER G SOBOL

Boehringer Ingelheim Ltd,,

PO Box 368, Ridgefield, 勻

Connecticut 06877, USA 